\title{
PROCESSO AVALIATIVO NA PEDAGOGIA SUPERIOR: REFLEXÕES FILOSÓFICAS SOBRE O ENSINO
}

\section{ARTIGO ORIGINAL}

SANTOS, Genivaldo dos ${ }^{1}$

OLIVEIRA, José Fernando Lima de ${ }^{2}$

SANTOS, Genivaldo dos. OLIVEIRA, José Fernando Lima de. Processo avaliativo na pedagogia superior: Reflexões filosóficas sobre o ensino. Revista Científica Multidisciplinar Núcleo do Conhecimento. Ano 05, Ed. 12, Vol. 08, pp. 111-126. Dezembro de 2020. ISSN: 2448-0959, Link de acesso: https://www.nucleodoconhecimento.com.br/educacao/reflexoes-filosoficas

\section{RESUMO}

A arte de avaliar, ainda hoje, é compreendida por muitas pessoas como um simples meio de medir ou atribuir um valor à capacidade dos alunos por meio de notas, ou conceituá-los no término de um curso, etapa ou tempo de formação, sem que se leve em consideração a preparação à vida e para a sociedade. Este trabalho tem como

${ }^{1}$ Mestrando em educação pela UDE-UY, Pocitos, pós-graduado em ética e filosofia (2011), pelo Instituto de Ciências Humanas João Paulo II, Caratinga/MG, pósgraduado em docência do ensino superior (2018), pela Faculdade do Planalto Central, Formosa/GO licenciado em filosofia, pelo Seminário Maior Nossa Senhora da Conceição, (2003) Aracaju/SE, convalidado (2012) pela Faculdade Batista Brasileira, Salvador/BA. Licenciado em teologia pelo Seminário Maria Mater Ecclesiae do Brasil (2007), Itapecerica da Serra/SP, convalidada (2017) pela Universidade Católica do Salvador, Salvador/BA.

${ }^{2}$ Mestrando em educação pela UDE-Pócitos-UY. Pós-graduado latu senso em saúde mental pela UCDB (2014) e graduado em psicologia pela Universidade Potiguar (2011). 
objetivo refletir e compreender o processo avaliativo no tocante ao que é avaliar, além de contextualizar a avaliação de qualidade e sua excelência no mundo acadêmico na cultura brasileira, tendo o cuidado para não reduzir o avaliar a uma simples e mera forma de medir a capacidade ou o ser da pessoa e as novas estratégias a serem utilizadas para que seja assegurado um ensino-aprendizado realmente efetivo. Para tanto foi necessário um trabalho acurado por meio de pesquisa e revisão bibliográfica, utilizando-se de diversas obras, trabalhos, aportes teóricos e tantos outros subsídios que abordam os assuntos aqui especificados. Como resultados esperamos ter aberto e apontado possibilidades para uma discussão a respeito do processo avaliativo do ensino superior que estejam voltados para um caminhar avaliativo, no qual se verifique a qualidade e não unicamente a quantidade do processo de ensino-aprendizagem, como também mostrar novos horizontes e metas a serem atingidos e alcançados, nesta visão da avaliação como meio de elevar a pessoa ao mais alto grau de construção de si e da sociedade.

Palavras-Chave: Processo avaliativo, avaliação, práxis pedagógica, docente, conhecimento.

\section{INTRODUÇÃO}

O ser humano quer no pensar e quer no agir, assim como toda realidade que o cerca, estão sujeitos durante toda a sua existência a algum tipo de avaliação. Onde quer que esteja, na escola, no trabalho, no seu modo de ser e agir socialmente, no processo do vestibular, nas atividades de cunho esportivos, na tentativa de uma vaga de emprego, etc. É a avaliação que serve de base e critérios cientificamente válidos tanto ao aluno quanto ao professor para que, por meio do desenvolvimento das tarefas realizadas, vejam o sucesso, os fracassos, as limitações, as lacunas existentes, e assim aprimorem as ações a serem concretizadas. Nesta mesma linha de pensamento Belloni (2001) defende que avaliar é uma ação cotidiana e espontânea realizada por qualquer indivíduo acerca de qualquer atividade humana. Assim sendo, também pode ser considerado um instrumento fundamental para conhecer, aperfeiçoar e orientar as ações dos indivíduos. É uma forma de olhar o passado e o presente sempre com vistas ao futuro. Faz parte dos instrumentos de sobrevivência de qualquer indivíduo 
ou grupo, resultado de uma necessidade natural ou instintiva de sobreviver, evitando riscos e buscando prazer e realizações.

Esta é uma prática constantemente exercida no âmbito educacional, pois se percebe que cada vez mais se firma e floresce uma constante busca avaliativa na prática dos educadores, por uma avaliação que se apresente de modo diferenciado e de qualidade, na qual se perceba que os meios e os fins a serem alcançados sejam claros e bem definidos e, não como tem sofrido influência externa em cada período e época. Para que haja um ensino de qualidade é necessário que se faça a aplicabilidade de métodos de avaliação que tenham plausibilidade para que possa ganhar um lugar de destaque no âmbito pedagógico e dentro do processo da arte de ensinar e aprender. Neste sentido, muito se acredita que a avaliação não é um ato meramente técnico, que apresente distanciamento do trabalho pedagógico de toda escola, todavia tem significativas reverberações em toda carreira escolar e na trajetória pessoal do estudante. Por isso a importância de analisar, refletir e questionar uma educação a nível superior que tenha um viés avaliativo que vá além de uma simples maneira de aplicação de exames e provas, que requeira uma melhor e maior definição dos valores educacionais e, ao mesmo tempo, apresente a complexidade e importância que tem no processo ensino-aprendizagem.

Diante disso, constata-se que avaliar consiste em não somente fazer uma coleta de dados de modo quantitativo é preciso inserir o qualitativo também, a ponto de fornecer ao professor não só uma ideia de quem seja o aluno e o como este vem desenvolvendo a sua capacidade de pensar e aprender, além de rever por meios de novos métodos, formas de ensino e avaliações, a sua prática cotidiana, possibilitandoo a superar os desafios e obstáculos que vão surgindo a todo o momento.

Neste sentido, há uma nítida percepção de que a avaliação da aprendizagem dentro de um processo político-pedagógico exerce a função não somente de aferir ao sujeito uma nota, mas de levá-lo a se ver como um ser de transformação e o seu papel transformador, por meio da educação, do seu próprio habitat e de toda uma sociedade. Para tanto é preciso o exercício de uma reflexão crítica que leve a pessoa a ter clareza da importância que tem a atividade pedagógica e escolar, não só para o 
aprimoramento do ensino-aprendizagem, que passa por um diagnóstico que busque cada vez mais um aprimorar da prática de ensinar e aprender. Esta atividade deve ressaltar a relevância das observações do dia a dia sem ficar engessado nas análises a priori do quociente quantitativo, mas também favoreça ao desenvolvimento social. É preciso que, muito mais do que visar às provas, o educador busque observar analítica, crítica e previamente, tanto o seu próprio desempenho e desenvolvimento, quanto do aluno, com dinamismo, interação numa mútua participação, de maneira que educador e educando alcancem resultados produtivos e positivos.

Neste artigo buscou-se fazer, num primeiro instante, uma abordagem sobre o conceito de avaliação, mesmo que de modo simples, uma vez que tal temática é muito abrangente e complexa; e uma contextualização do universo acadêmico e sua maneira avaliativa apontando os vastíssimos desafios em que os professores são chamados a encarar para não reduzir a avaliação a um mero sistema de atribuição de notas. Trataremos, ainda, da avaliação e suas funções, da qualidade avaliativa em detrimento somente da quantidade ou meios de avaliar, como também das estratégias utilizadas pelos docentes na hora de avaliar. Por fim, as considerações finais trazem uma análise na qual abre possibilidades para uma discussão a respeito do processo avaliativo do ensino superior, no qual somente se a aferição de um conceito por meio de nota, cujo resultado é o final e não como instrumento de desenvolvimento, fazendo a reflexão sobre este conceito, inquietando os atores envolvidos a buscarem novas e dinâmicas estratégias de avaliação para o ensino.

\section{AVALIAÇÃO NA PEDAGOGIA SUPERIOR}

O indivíduo é capaz de atingir o saber através da especulação, observação, execução com isso passa a compreender, interpretar, refletir, julgar e avaliar as coisas, pessoas e a sua própria condutada, fazendo da avaliação uma práxis constante. Assim sendo, o ser humano é levado a tecer juízo de valor a todas as realidades, circunstâncias da vida, pessoas e até mesmo avaliar o grau de aprendizado que cada pessoa tenha atingido. No tocante ao universo educacional, mais precisamente ao nível superior, não é diferente, pois constantemente o professor e o aluno vivem avaliando tudo em sua volta. Desta forma, avaliar é um agir inerente às ações do homem e deve ser 
compreendida como uma prática social, não puramente individual, e que vislumbre avanços e florescimentos. Compreendemos que avaliações feitas devem-se assumir como um mecanismo de se pensar uma dada situação, tendo em vista o crescimento e não a estagnação disciplinadora (BOGGINO, 2009). Muitas vezes e de maneiras diferentes a avaliação, imersa e praticada no universo acadêmico, tem a tentação de cair em um mero reducionismo, perdendo de vista seus objetivos fundamentais, tornando-se assim um mero instrumento ou meio de atribuir notas ou conceitos aos alunos no término de um curso, como Villas Boas et al (2017) diz que "torna-se necessário nos distanciemos das práticas somativas de avaliação e andemos em direção a práticas mais formativas. Portanto, devemos usufruir de instrumentos múltiplos para tal". O reducionismo a provas e somas somente cria uma mentalidade de retenção, sem que este se torne um agente de decisão e transformação da realidade que vive e the circunda:

A avaliação do desempenho dos estudantes não deve ter o propósito de promoção ou retenção. Por se tratar de vivencias e oportunidades para o desenvolvimento das múltiplas dimensões humanas, o desempenho dos estudantes deve ser registrado em instrumentos e/ou observado por meio de procedimentos que favoreçam o acompanhamento desse processo mais complexo e amplo (SILVA, 2017, p. 45).

Todavia, importa pensar como a avaliação vem sendo aplicada e experienciada nos ambientes de aprendizagem. Muitas vezes há uma aplicação de uma avaliação que promove a culpa, no qual os resultados almejados e alcançados são apenas mera classificação de alunos bons ou péssimos, quando na verdade este mecanismo deve levar à superação das dificuldades e de um regime arcaico. Com este regime, emergem múltiplos questionamentos, discussões e debates sobre a forma ou o melhor meio de avaliar tanto o ensino, quanto a aprendizagem das pessoas na educação de ensino superior. É necessário um olhar mais amplo na discussão, que levem seus interlocutores a desenvolverem, de modo crítico, analítico e reflexivo, vários meios que favoreçam a construção de novos parâmetros, bases curriculares contínuas para uma boa avaliação, assim sua função vai muito além de executar testes e usar seus resultados de maneira competitiva, tornando-se uma ferramenta útil num processo 
contínuo de reflexão acerca das aprendizagens estudantil e sobre o trabalho pedagógico.

Hoffmann (2018) nos presta valorosa colaboração ao verificar que a avaliação tem se caracterizado como disciplinadora e discriminatória, como decorrência, gerando por consequência a ação corretiva do professor e os enunciados que emite a partir dessa alteração. Todavia, sustentamos a ideia de que a avaliação possibilite tanto aos mestres quanto aos alunos, meios que os façam enxergar que são seres que avaliem e atuem de forma não somente com a finalidade quantitativa, mas qualitativa e que contribuam para o bom andamento, desempenho e construção do saber como um todo. Dias e Soares apud Villas Boas (2017) observam que os professores universitários são aqueles que experienciam muito mais os constantes e múltiplos desafios, entre eles o de decidir sobre o como avaliar, compor novos currículos, traçar meios e metas que de modo estratégicos não venham a se fechar em uma única forma de avaliação improdutiva, mas que venham dar respostas e de acordo com estes pesquisadores trazer maiores possibilidades de dar à pessoa e ao grupo condições de refletirem sobre ações que transformem toda uma realidade:

Avaliar o trabalho realizado é o que dará condições ao grupo de refletir sobre ações necessárias para o alcance dos objetivos traçados, mantendo o que está certo e revendo aquelas ações que pouco contribuíram ou interferiram no processo de ensino-aprendizagem. Assim, a avaliação deixa de ter um fim em si mesma e tem maiores possibilidades de se efetivar como processo avaliativo-formativo. (pág. 57)

No ensino superior tradicional percebe-se, de modo geral, uma avaliação que se dá num processo de escolhas que se limitam a estratégias fundamentadas em apenas avaliar de modo somativo ao fim de cada período semestral ou ano letivo de intergeracional do ensino. Para Brown e Abeywickrama (2010) o modelo de avaliação atual consiste geralmente de provas padronizadas, com múltiplas questões e por vezes com itens descontextualizados e tendo por base um produto. Tal procedimento consiste em um meio avaliativo arcaico e que simplesmente visa à execução da avaliação por meio de provas escritas, limitando outros meios eficazes que possam absorver o grau de aprendizagem de cada indivíduo. Estes mesmos estudiosos 
chamam a atenção para a existência de uma forma predominante que perpassa por todo processo de avaliação na aprendizagem, assegurando, com isso, o desenvolvimento global do alunado, sendo vista nas mais variadas formas e escolhas do mundo pedagógico e, ao mesmo tempo, as legislações que norteiam a educação, LDB 9394/96, assegura, no artigo $2^{0}$ que a educação é dever da família e do estado, tendo por princípios a liberdade e ainda os ideais de solidariedade humana, gerando ao seu final o desenvolvimento completo dos alunos, seu preparo para o exercício da cidadania. Desta forma, a avaliação deve ser um meio pelo qual os professores possam diagnosticar problemas existentes e, do mesmo modo, apontem metas que estejam voltadas para uma maior qualidade almejada, não definitiva, e que não venha a rotular ou classificar entre bons e ruins, fazendo uma separação ou divisão de classe, mas ajudar na superação dos déficits educacionais.

Nesta mesma direção, os Parâmetros Curriculares Nacionais (PCNs), se voltam para a orientação da educação, propondo nortes que venham iluminar o como avaliar. Sendo assim, se abre horizontes que visam clareza nas definições e avaliação que almeja atingir sua objetividade, maior consideração na pluralidade das ferramentas a serem trabalhadas, dos meios e situações que possibilitam, de modo crítico, analítico e imparcial, uma avaliação das capacidades mais variadas possíveis e que visem com transparência à aprendizagem em cada contexto como também o uso de códigos diferenciados que levem à reflexão das condições dos educandos. Códigos esses que abrangem a verbalidade, oralidade, a escrita e tantos outros. Segundo este pensamento, pode-se dizer que o educador tem vários mecanismos que ajudam fazer uma avaliação consistente sem se fechar no dogmatismo do qualitativo, mas que contemple o quantitativo que se pretende atingir. É de suma importância lembrar que a avaliação não é algo restrita e de propriedade unicamente do professor, pois, nos PCNs, tal responsabilidade deve ser delegada também aos alunos como um meio que possibilite a cada um fazer a sua própria auto avaliação e uma autocrítica e da qualidade do que já foi aprendido.

Insistir na ideia de uma avaliação global e não parcial faz reforçar a compreensão, para que haja um processo avaliativo seguro, da necessidade de critérios confiáveis 
que levem a analisar os aspectos a serem avaliados no seu conjunto, para gerar uma efetiva aprendizagem. O conteúdo, a aplicabilidade, a maneira, a forma da aprendizagem tem que trilhar em um mesmo sentido ou direção, isto é, a condução dos alunos a uma reconstrução do seu próprio eu e da sociedade democrática, assim destaca Sobrinho (2008, p. 194):

[...] Deve construir os campos sociais de discussão e valoração a respeito dos processos, contextos, produtos, objetivos, procedimentos, estruturas, causalidades, metas de superação, condições de produção das atividades educativas, sentidos e impactos na formação dos cidadãos e na construção da sociedade democrática.

Nesta perspectiva, esta visão sobre a avaliação impulsiona aos alunos a conquistarem metas, desenvolvendo atividades educativas que os impactam de maneira positiva a ponto de formar suas próprias consciências na construção e transformação do meio social em que vivem de modo verdadeiro. Dias apud Villas Boas (2019, p. 107) defende uma avaliação que almeje uma linha, que busque a aplicabilidade dos objetivos, conteúdos propostos para a disciplina, ou para o curso; o conhecimento e desenvolvimento cognitivo, afetivo e social em cada passo dado pelos alunos fazendo com que estes não vivam presos ao seu mundo intelectual, mas desenvolvam processos de socialização: "desse modo, o processo avaliativo é mais amplo e abrangente, considerando os aspectos afetivos e psicomotores, além do domínio cognitivo (relacionados ao aprender, dominar um conhecimento)".

Portanto, se o educador vive preso a uma simples forma de desenvolver códigos educacionais baseados unicamente em promover a competitividade, a seleção de alunos, desprovida de um olhar mais amplo que apontem novos horizontes e estreitem as relações sociais e que seja livre de preconceitos ou exclusões, torna-se um empecilho ao próprio desenvolvimento e aprendizagem.

\section{COMPREENSÃO DA AVALIAÇÃO}

Existe uma mentalidade que norteia o entendimento e aplicação do processo avaliativo no qual, alguns professores, compreendem a avaliação como tipos de testes, exercícios, provas ou trabalhos, sem levar em consideração a amplitude da 
aprendizagem e sem separar do todo que envolva responsabilidade e reciprocidade na relação professor-aluno. O projeto de lei 142/2018 do Senado Federal, no Artigo 2 $\S$ VII, assegura que para que haja uma maior compreensão da aprendizagem, digase da avalição, de qualidade, é preciso aprofundar o envolvimento relacional entre os atores envolvidos. Também Da Rosa e Dos Santos Kehler (2020), afirmam que o professor tem toda possibilidade de desenvolver uma empatia pelos alunos, tendo assim mais chances de construir vínculos, conseguindo compreender se eles aprendem ou não. Se a avaliação é aceita e tratada somente nos moldes tradicional, ela vai cada vez mais se distanciando de seus objetivos, da sua íntima ligação com o ensino-aprendizado, deixando de ser algo crítico e analítico. Por sua vez, Matias (2019) endossa que a aprendizagem só tem real sentido quando se faz de forma lógica para os estudantes, só assim o aprender se torna consciente, congruente. No Plano Nacional de Educação (PNE), no discurso de prelúdio aponta o verdadeiro e significativo papel dos professores frente aos seus alunos:

Orientar e mediar o ensino para a aprendizagem dos alunos; responsabilizar-se pelo sucesso da aprendizagem dos alunos; assumir e saber lidar com a diversidade existente entre os alunos; incentivar atividades de enriquecimento curricular; elaborar e executar projetos para desenvolver conteúdos curriculares; utilizar novas metodologias, estratégias e material de apoio; desenvolver hábitos de colaboração e trabalho em equipe (BRASIL, 2000).

A partir disto, podemos notar como o conceito de avaliação pode ser repensado de modo que atenda os novos rumos e as necessidades de referenciais atualizados que reorganize todo um processo avaliativo eficaz. Desta maneira se chega a uma deliberação da avaliação como algo que parte de uma realidade mental e que abre às variadas possibilidades de aprendizagem. Diante desta visão Hoffmann (2003), assume que avaliação significa o controle integral sobre a prática do aluno, no objetivo dele chegar a demonstrar comportamentos definidos como ideais pelo professor. Com estes conceitos, compreende-se a grande importância de uma avaliação que aperfeiçoe e aprimore o processo de ensino-aprendizagem, baseando-se no desenvolvimento, desempenho e transformação no modo como entender e enxergar a realidade por parte de cada aluno. Se a avaliação não for um processo democrático no qual vise $o$ aluno em todas as suas fases e aptidões e que por meio de uma 
metodologia ampliada, renovada e aberta a novos horizontes, seja um veículo de transformação, esta será algo que comprometerá não somente a qualidade do ensinoaprendizagem, como também não contribuirá tanto na superação dos obstáculos existentes.

A avaliação pode ter uma função muito além de fazer um juízo de valor, bem como superar uma separação de classes entre os que são mais capazes e inteligentes dos que não o são. Antes de tudo, as funções que cabem à mesma são: 1) Fazer um levantamento de toda realidade que engloba e existe em torno daquele que será avaliado, por meio de um diagnóstico; 2) Realizar um controle por meio de classificações, não somente de partes da realidade, mas de um vasto conjunto repleto de diferentes modos e maneiras e que seja eficiente e eficaz no processo avaliativo; por fim ter a avaliação como diagnóstica, formativa e somativa. A diagnóstica é a que faz uma análise prévia dos conhecimentos do aluno dentro de um processo de construção. A partir desta o professor tem a possibilidade e capacidade de ver se os educandos estão mais aptos para a aquisição de novos conceitos e conhecimentos, e, ao mesmo tempo, tem subsídios fundamentados para que se identifiquem os obstáculos e dificuldades existentes nesse itinerário de aprendizagem. A formativa se volta para a aplicação no desenvolvimento do processo de ensino-aprendizagem, tem como meta o controle e informa ao educador e ao educando os resultados da aprendizagem e a somativa tem como objetivo, ao chegar ao final do curso, classificar quantitativamente mediante o aproveitamento obtido. Tal direcionamento deve visar não somente os objetivos individuais, mas também o grupal. Esta é a modalidade utilizada para obter resultados que distingam os sábios dos néscios, classificar ou desclassificar (BLOOM apud SANT'ANNA, 2002).

Feita esta análise das funções ou modalidades se chega à compreensão, no entender de Pinheiro (2018), que a aprendizagem está ligada à performance do ensino, na qual tende suprir o aluno individual, emocional ou socialmente. Sendo assim, o professor tem o dever de desenvolver o seu papel problematizando as realidades já vistas, fazendo com que os alunos entrem na dinâmica de um processo que os levem a construir os conhecimentos próprios, tendo como base os conteúdos já estudados, e 
que tenham ainda seu olhar voltado para o contexto histórico, social, psicológico e político em que se vive. Nesta perspectiva se chega à igualdade entre o mestre e discípulo, no sentido de não se fixar somente na ideia de que neste interim educacional e avaliativo só um é transmissor do conhecimento e, nesse caso o professor. Hoffmann (2018) vai dizer que o dia a dia em avaliação, pede, portanto, um tempo de deixar falar, tempo de relatar situações, contar histórias, sem a delimitação de objetivos previamente estabelecidos, temas a priori determinados, análises críticas imediatamente feitas.

A partir deste pensamento, podemos supor que a avaliação pode garantir não somente a eficiência, mas também a eficácia em todo seu processo, fazendo com que o aluno reconheça os próprios erros e acertos, limites e possa estabelecer critérios que possam dar as respostas corretas aos vários questionamentos. A avaliação é chamada a analisar e julgar as dimensões do comportamento do aluno não só de modo parcial, mas integral e que atinja um equilíbrio em sua complexidade. Uma vez que a concepção de uma avaliação que busca controlar seja o agir ou o comportamento dos alunos, em sala de aula, e a organização do estabelecimento de ensino, realizada pelos professores, ou pela instituição governamental, torna-se uma relação não de liberdade, mas sim uma avaliação dominadora e repressora e que "[...] contribui para fabricar imagens e representações sociais positivas que, consoante os casos, levam à promoção ou estigmatização dos alunos, justificando a sua distribuição diferencial na hierarquia escolar". (AFONSO, 2000, p. 21).

O educador deve passar por um processo avaliativo constante de suas ações que 0 leve a indagar, investigar, mudar as suas práticas, caso estas estejam ultrapassadas, para uma docência que não se feche ao absolutismo. Contudo, avaliar é um ato racional, reflexivo, crítico, analítico que transforma as ações, liberta o indivíduo e faz uma sociedade progredir.

\section{AVALIAÇÃO QUALITATIVA E A SUA EXCELÊNCIA}

Ao longo do tempo e da história o termo avaliação foi compreendido como um simples ato de medir, julgar, classificar, desclassificar incluir ou excluir, por meio de exames e 
provas os quais controlam o quantitativo daquilo que deve ser aplicado no processo de ensino- aprendizagem, entretanto a partir de pesquisadores que foram discutidos acima, podemos compreender que esta também exerce a função de apontar, passo a passo, o êxito ou não do mesmo processo. Caso tal processo não alcance os resultados almejados, a avaliação pode indicar as mudanças que devem ser realizadas no desejo de conseguir assegurar a eficácia da aprendizagem, antes que o caminho percorrido seja esfacelado.

$\mathrm{Na}$ avaliação também encontra outros aspectos a serem analisados e que têm grande relevância, logo, é um processo não estático, mas contínuo, bem como é sistemática, compreensiva, comparativa, cumulativa, informativa e geral, pois tem a capacidade de permitir que o conhecimento dos alunos seja avaliado. Ela não se encaixa numa visão que a leve a ser feita de modo esporádico e nem tão pouco de improviso. É constante, e necessita passar por um planejamento que possibilite a capacidade de um diálogo e sempre se recupere quando necessário. A avalição não se encerra em si mesma. Não é um instrumento final e sim, é meio, recurso que se bem utilizado, garante o sucesso. Nesta perspectiva se chega à compreensão de que o educador não deve fixar o seu olhar e gastar toda a sua energia na busca de resultados adquiridos por intermédio de provas periódicas que tenham caráter unicamente classificatório, mas acima de tudo leve em consideração a supervalorização das observações diárias, de compreensão de caráter diagnóstico e que trabalhe de maneira dinâmica, interativa, participativa e que considere a produtividade dos alunos. Pode-se perceber que o modo pelo qual os alunos estudam e aprendem os assuntos apresentados no dia a dia, está intimamente ligado à metodologia de ensino e à avaliação feita pelo professor. Neste sentido os educandos creem que o modo de proceder, os instrumentos, os recursos utilizados, os resultados das discursões alcançados, os trabalhos desenvolvidos e modo que os levem a interagir, tudo isso faz parte do processo e do desenvolvimento da aprendizagem (BOGGINO, 2009).

Vale frisar que o mais importante não é somente a mudança na forma de avaliar por parte do professor que venha a garantir a melhor qualidade da avaliação e do aprendizado dos alunos. É perceptível que, em alguns momentos, as ações 
desenvolvidas tragam os resultados pretendidos pelo professor e, ao mesmo tempo, que estes consigam elaborar planos e busquem instrumentos úteis para o avanço do ensino. Na concepção dos alunos, a avaliação simplesmente não passa de ser considerada como um meio de medir, verificar a sua aprendizagem, seus conhecimentos.

É bem visível que em muitos estabelecimentos educacionais se encontrem práticas comumente de avaliar através de caderneta de notas como contabilizar os resultados e não os verificando para corrigi-los se assim for preciso. Pode - se dizer que a avaliação é uma ação que compromete a concretização do projeto educacional, pois avaliar, na cabeça dos alunos, é entendido tão somente como uma repreensão e fiscalização tanto do professor, como da escola. É urgente que haja meios que rompam, quebrem os preconceitos e os padrões estabelecidos que foram determinados ao longo da história, para que se alcance uma nova visão e compreensão de avaliação. Aplicar outros meios de avaliar, quer dizer mudar as visões erradas das instituições, quebrando e rompendo os paradigmas, o que possibilitaria uma ação mais qualitativa do que quantitativa.

Tradicionalmente falando, avaliar remete à antiga crença em que os professores acreditavam que quem garante o bom sucesso da ação avaliativa seria a maneira classificatória de um ensino qualitativo. Tal ideia não é somente de alguns professores, mas algo defendido pela sociedade, que não se abre às novas formas e meios no ensino - aprendizagem. Para justificar o que aqui fora apresentado, Rabelo (1998, p. 80) diz que:

De fato, falar de avaliação qualitativa é falar do compromisso ético e formal do professor em garantir condições para a melhor aprendizagem possível. (...) Por isso, se a avaliação se restringir apenas a função de controle, sua função ficará descaracterizada. Passaremos a avaliar para atribuir um resultado e o aluno passará a estudar, apenas para obter uma nota.

Sabe-se que se faz necessário rever o processo tradicional de avaliação, ou seja, é preciso fazer da avaliação um método inovador, transformador e que não fique estagnado. Esta é uma tarefa difícil, pois o meio social desaprova e colocam até em 
descrédito os estabelecimentos educacionais que pensa e haja diferente das estruturas antigas. Todavia a novidade e a mudança causam receios, pois frente a tudo que é novo, é muito mais fácil se manter numa falsa opulência de uma zona de conforto. Assim, existe muita resistência à aplicabilidade de um processo renovado, a ponto de muitos professores recorrerem, na hora de avaliar, aos métodos tradicionais. Para Demo (1999, p.36,37):

Toda avaliação qualitativa supõe no avaliador qualidade metodológica. Isto significa ponto de partida que não faz nenhum sentido desprezar o lado da quantidade, desde que bem feito. Só tem a ganhar a avaliação qualitativa que souber cercar-se inteligentemente de base empírica, mesmo porque qualidade não é a contradição lógica da quantidade, mas a face contrária da mesma moeda. [...] Mais do que nunca pesa sobre avaliações qualitativas o desafio do discurso rigoroso, meticuloso, medido, logicamente planejado. A diferença está em que este rigor, para os que buscam qualidade a sério, não passa de instrumentação.

Ao longo de todo processo do ensino - aprendizagem, os educadores no desejo de dar respostas aos vários questionamentos e soluções para os vastíssimos problemas, de seus alunos foram experienciando e abraçando técnicas e meios que os ajudassem a resolvê-los. Porém, por não buscar um diálogo com os alunos que Ihes possibilite a um olhar amplo, levando em consideração o penar, agir, ser e refletir dos alunos, em seu cotidiano, os professores caem novamente na armadilha do retorno aos antigos manuais educativos que os levam a avaliar de modo ainda reduzido. Avaliar não é tolher a espontaneidade e liberdade dos alunos, mas sim fazer com este desenvolva sua capacidade, autocriticidade e a sua autonomia para que a partir de princípios já vistos possam desenvolver novos conhecimentos e compreenda que o ensinoaprendizagem exerce grande importância. Além de possibilitar aos alunos a construção, por meio de argumentações e raciocínio lógico do conhecimento e ao mesmo tempo compreendam, de modo novo, o que outras pessoas já discutiram, apontando novos horizontes e metas que transformem a sociedade. Nesta direção, Hoffmann (1993) salienta uma avaliação de qualidade a qual denote ação provocativa docente, desafiando o aluno a pensar acerca das situações vividas, a formular e reformular hipóteses, encaminhando-se a um saber amadurecido. Por conseguinte, conversar é pensar em conjunto acerca do propósito do saber. Pede-se um 
aprofundamento em teorias de conhecimento e nos múltiplos saberes. Por certo, andar junto é favorecer o vir a ser, promovendo ações educativas que deem lugar novos horizontes.

A partir disto, podemos analisar que o que torna possível um bom acompanhamento no processo evolutivo de cada aluno é que a nota seja uma maneira impulsionadora para um bom diagnóstico da aprendizagem, e não um mero enquadramento de valor que empurre o aluno para o sucesso pessoal e social. Os bons resultados dos alunos em cada avaliação devem ser cada vez mais discutidos e ampliados por meio de debates, seminários, fóruns e tantos outros meios que possibilitem grandes progressos ao conhecimento. Portanto requer a participação de todos os envolvidos e interessados no processo de ensino- aprendizagem, sendo que é a educação superior que tem o papel fundamental de analisar, desenvolver, consolidar e levar à edificação da cidadania, da liberdade e da transformação do sujeito e da sociedade como um todo. (BARREIRA; BOAVIDA E ARAÚJO, 2006).

\section{CONSIDERAÇÕES FINAIS}

Em se tratando do processo educacional de ensino- aprendizagem em sua totalidade pode-se dizer que tal prática seria incompleta, ineficaz, rotuladora e opressora se não existisse um momento avaliativo para o progresso da educação e da sociedade. Por viver em um universo em que o ser humano constantemente avalia e é avaliado se torna fundamental a importância que em todo curso, escola, família, busca de emprego ou em toda e qualquer realidade que cerca o ser humano na sociedade haja a avaliação. Sabemos que muitas vezes avaliar se torna alvo de crítica negativa, desconstrutiva e até indesejada não somente pela maior parte dos alunos, mas também da grande maioria dos agentes sociais. Mesmo assim não se pode abrir mão da avaliação, auxiliada pela variedade de recursos, informações, uma vez que esta é parte integrante, para que se tenha um bom desenvolvimento, funcionamento e organização do cenário acadêmico.

Hoje em dia há uma maior percepção de que cada vez mais se vem conquistando muitas mudanças significativas e necessárias no meio acadêmico. No tocante da 
avaliação, o docente, ao invés de ser um mero transmissor de conteúdo e informações, ou de ser aquele que era considerado o detentor de todo saber e da verdade, se torna a cada dia aquele que facilita e impulsiona os alunos, a construírem e conquistar novos conhecimentos. Por isso a avaliação é apresentada como instrumento que liberta e que visa maior qualidade do ser, fazendo com que este atue de modo positivo e construtor de uma nova visão social, necessita ser enxergada, compreendida e defendida como um estímulo que dê base e eleve o aluno no âmbito da superação de suas limitações acadêmicas e sociais. Logo, é de suma importância ratificar que o termo avaliar não seja visto pelo educando como mecanismo que venha punir, classificar de maneira excludente e/ou menosprezar o aluno que está numa constante construção de si, dos seus valores, das pessoas e do mundo. Do mesmo modo, também represente objeto de escravização no qual gere desconfiança e desconforto entre professor e aluno, deixando de exercer a sua finalidade e eficácia, que enquadre tão somente, como um simples meio que busca resultados que geram atrofiamento e exclusão no processo avaliativo de ensino-aprendizagem.

Muito mais do que refletir, importa ponderar os aspectos qualitativos os quais norteiem a avaliação, garantindo e assegurando procedimentos cabíveis aos alunos para que tenham possibilidades de desenvolvimento, assim a avaliação no ensino superior torna-se flexível no que diz respeito a proporcionar melhorias e desenvolver as habilidades para o alcance dos objetivos das suas funções, isto é, apresentar subsídios que aperfeiçoe o ensino- aprendizagem. Do mesmo modo, a avaliação pode representar a abertura de novos caminhos e horizontes, para uma aplicabilidade consistente e plausível do processo de aprendizagem, não somente do ensino superior, mas de todo o universo educacional que esteja voltado para um caminhar avaliativo, e que tenha como base a finalidade da qualidade e não unicamente a quantidade do ensino.

Em virtude de tudo isto, que novos ventos soprem sobre a educação e que o processo avaliativo aponte metas ao professor dando-Ihe capacidade de fazer uma maior reflexão sobre a sua metodologia de trabalho e a sua forma de avaliar, para que perceba o aluno não como depositário de conteúdos bem como veja suas dificuldades. 
Destarte leve o discente a despertar e desenvolver suas capacidades de pensar, criticar, refletir e transformar a sociedade, com pleno conhecimento dos seus direitos e deveres.

\section{REFERÊNCIAS BIBLIOGRÁFICAS}

AFONSO, Almerindo Janela. Avaliação educacional: regulação e emancipação. São Paulo: Cortez, 2000.

BARREIRA, Carlos; BOAVIDA, João; Araújo, Nuno. Avaliação formativa Novas formas de ensinar e aprender. Revista Portuguesa de pedagogia. Ano 40-3, 2006, 095-133. Disponível em: https://www.researchgate.net/ - Acesso 02/01/2020.

BELLONI, Maria Luiza. O que é mídia-educação. São Paulo: Autores Associados. 2001.

BOGGINO, Norberto. A avaliação como estratégia de ensino: avaliar processos e resultados. Sísifo. Revista de ciências da educação. №9. mai/ago 2009. Disponível em: files//home/chronos/ - Acesso dia 02/01/2020.

BRASIL. Plano Nacional de Educação (Lei n.ํ 10.172/01). 2000.

BROWN, H.D. e ABEYWICKRAMA, P. (2010). Language assessment: Priciples and classroom practices. $2^{\underline{a}}$ ed. White Plains: Pearson Education.

DA ROSA, N; DOS SANTOS KEHLER, G. Aspectos da teoria do professor facilitador de Carl Rogers: implicações na educação escolar contemporânea. Anais do Salão Internacional de Ensino, Pesquisa e Extensão, v. 7, n. 1, 12 fev. 2020.

DEMO, Pedro. Avaliação Qualitativa. Campinas: Autores Associados, 1999.

HOFFMANN, Jussara. Avaliação mediadora: uma prática em construção da pré escola à universidade. 21를 Ed. Porto Alegre: Mediação, 1993. 
Avaliação - mito e desafio: uma perspectiva construtivista. $41^{\circ} \mathrm{ed}$. Porto Alegre: Educação e Realidade, 2003.

Avaliação Mediadora: uma prática em construção da pré-escola a universidade. 34르 ed. Porto Alegre: Educação \& Realidade, 2018.

MATIAS, E.de L; LACERDA, R. G. de; OLIVEIRA, C. A. de; RODRIGUES, A. de C. F. A Contribuição da Teoria Humanista para a Formação Integral do Aluno. DOI: 00.0000/0000-0000.2018x0y0z0. (2019)

MEC - Ministério da Educação e Cultura, Avaliação da educação superior. Disponível em: <www.mec.gov.br/sesu/pdf/sinae.pdf>. Acesso em 20 ago 2020.

PCN, Parâmetros Curriculares Nacionais, Disponível em <www.mec.gov.br/seb/>. Acesso em 28 dez 2017.

PINHEIRO, Marlene \& Batista, Eraldo. (2018). O aluno no centro da aprendizagem: uma discussão a partir de Carl Rogers. 7. 70-85.

RABELO, Edmar Henrique. Avaliação: novos tempos, novas práticas. Petrópolis: Vozes, 1998.

SANT'ANNA, I. M. Por que avaliar? Como avaliar? Critérios e instrumentos. Petrópolis, RJ: Vozes, 1995.

SENADO FEDERAL. Projeto de lei 142 de 2018. Institui a Política de Inovação Educação Conectada; e altera a Lei o 9.998, de 17 de agosto de 2000 e da outras providencias. Disponível: em <https://ww25.senado.leg.br/web/>.

SOBRINHO, José Dias. Avaliação educativa: produção de sentidos com valor de formação. São Paulo: Cortez, 2008.

VILLAS BOAS et al. Avaliação: Interações com o trabalho pedagógico. Campinas, SP: Papirus, 2017. 
VILLAS BOAS et al. Conversas sobre avaliação. Campinas, SP: Papirus, 2019.

Enviado: Junho, 2020.

Aprovado: Dezembro, 2020. 